\title{
Rationale for Timely Insulin Therapy in Type 2 Diabetes Within the Framework of Individualised Treatment: 2020 Update
}

\author{
Markolf Hanefeld · Holger Fleischmann - Thorsten Siegmund • \\ Jochen Seufert
}

Received: April 28, 2020 / Published online: June 20, 2020

(C) The Author(s) 2020

\section{ABSTRACT}

Type 2 diabetes is characterised by chronic hyperglycaemia and variable degrees of insulin deficiency and resistance. Hyperglycaemia and elevated fatty acids exert harmful effects on $\beta$ cell function, regeneration and apoptosis (gluco-lipotoxicity). Furthermore, chronic hyperglycaemia triggers a vicious cycle of insulin resistance, low-grade inflammation and a cascade of pro-atherogenic processes. Thus,

Digital Features To view digital features for this article go to https://doi.org/10.6084/m9.figshare.12413084.

M. Hanefeld $(\bowtie)$

Medizinische Klinik und Poliklinik III,

Universitätsklinikum Carl Gustav Carus, Dresden, Germany

e-mail: markolfhanefeld@gmail.com

H. Fleischmann

Diabetes and Cardiovascular, Sanofi-Aventis

Deutschland GmbH, Berlin, Germany

T. Siegmund

Diabetes-, Hormon- und Stoffwechselzentrum, Isar

Klinikum München $\mathrm{GmbH}$, München, Germany

J. Seufert

Division of Endocrinology and Diabetology,

Department of Medicine II, Medical Center-

University of Freiburg, Faculty of Medicine,

University of Freiburg, Freiburg, Germany timely near to normal glucose control is of utmost importance in the management of type 2 diabetes and prevention of micro- and macroangiopathy. The majority of patients are multimorbid and obese, with critical comorbidities such as cardiovascular disease, heart failure and chronic kidney disease. Recently published guidelines therefore recommend patient-centred risk/benefit-balanced use of oral glucose-lowering drugs or a glucagon-like peptide 1 (GLP-1) receptor agonist, or switching to insulin with glycated haemoglobin $\left(\mathrm{HbA}_{1 \mathrm{c}}\right)$ out of target. This article covers the indications of early insulin treatment to prevent diabetes-related complications, particularly in subgroups with severe insulin deficit, and to achieve recovery of residual $\beta$-cell function. Furthermore, the individualised, risk/benefit-balanced, timely initiation of insulin as second and third option is analysed. Timely insulin initiation may prevent diabetes progression, reduce diabetes-related complications and has less serious adverse effects. Basal insulin is the preferred option in most clinical situations with consequences of undertreatment of chronic hyperglycaemia.

Keywords: Basal insulin; Cardiovascular risk; Individualised therapy; Risk/benefit balance; Sarcopenia; Severe hypoglycaemia; Timely insulin therapy; Type 2 diabetes 


\section{Key Summary Points}

Chronic hyperglycaemia and elevated free fatty acids exert harmful effects on $\beta$-cell function and regeneration, as well as on the metabolic memory. Early insulinisation can delay or reverse residual $\beta$-cell function and loss, respectively.

The majority of patients with type 2 diabetes are multimorbid with diabetes-related complications. Seniors with frailty and sarcopenia as comorbidities, and subtypes with severe insulin deficit are candidates for patient-centred timely insulin treatment.

Studies in newly diagnosed diabetes with $\mathrm{HbA}_{1 \mathrm{c}}>8.5-9 \%$ and clinical symptoms with early initiation of insulin to achieve near to normal glucose control show longlasting remissions in up to $50 \%$. Some long-term studies (DIGAMI 1, UKPDSLegacy, ORIGIN) indicate significant benefit on microvessel disease, cardiovascular events, and in two studies with follow-up of more than 10 years an improved life expectancy.

Severe hypoglycaemia (SH) and weight gain are critical harmful side effects of inappropriate insulin therapy. There is a bidirectional interaction between $\mathrm{SH}$ and cardiovascular events. Thus, SH indicates a very high-risk group for cardiovascular events and deaths.

Timely initiation of insulin promotes better treatment to target glucose control with lower insulin dosage, lower rates of adverse events, and is cheaper. Insulin can be used as partner to oral antidiabetics except sulfonylurea, and to GLP-1 analogues, also as fixed combinations.

\section{INTRODUCTION}

Deficits in biphasic and pulsatile insulin secretion play a key role for manifestation and progression of type 2 diabetes. In the natural history of type 2 diabetes, impaired insulin secretion occurs long before diabetes is diagnosed $[1,2]$. Timely insulin therapy has been demonstrated to represent one of the most effective tools to protect pancreatic $\beta$-cell function, endothelium and other end-organs from harmful effects of hyperglycaemia [3, 4]. Even in patients with severe hyperglycaemia $\left(\mathrm{HbA}_{1 \mathrm{c}}>9-10 \%\right)$ at diagnosis, insulin is able to control gluco- and lipotoxicity within a few days of therapy by downregulating excessive peripheral insulin resistance, hepatic glucogenesis, lipolytic activity of adipose tissue, and subclinical inflammation [3-10].

There is substantial evidence that insulin treatment can lead to long-lasting recovery of residual pancreatic $\beta$-cell function [6, 7]. With early insulin therapy, durable remission of dysglycaemia was achieved in up to $50 \%$ of cases [8-11]. Moreover, in the ORIGIN study [12] and some other clinical trials it was shown that with early insulin treatment progression of diabetes was significantly reduced in comparison to standard of care $[13,14]$. A detailed analysis of the pathophysiology, underlying clinical reasoning and indication for early insulin treatment in type 2 diabetes has been given previously $[3,15]$. Of note, in obese patients with metabolic syndrome and insulin resistance, insulin therapy may also have adverse effects such as hypoglycaemia, weight gain and possibly increased risk of cardiovascular (CV) events, heart failure and arrhythmias. Moreover, insulin therapy needs professional medical care and may be associated with inconveniences for elderly patients.

In advanced diabetes with a duration of more than 10 to 15 years, residual pancreatic $\beta$ cell function is critically impaired as a consequence of long-lasting gluco-lipotoxicity leading to imbalance between $\beta$-cell regeneration and apoptosis $[14,16]$. Protection and recovery of residual $\beta$-cell secretory capacity, however, can reduce the risk of severe hypoglycaemia $(\mathrm{SH})[17,18]$. Consequently, there is evidence that timely insulinisation can prevent diabetesrelated complications, improve endothelial function and myocardial blood flow, and may 
protect end-organs from oxidative stress and glycosylation [19-22].

In 2008, the US Food and Drug administration (FDA) published its "Guidance for Industry" mandatory recommendations how new glucose-lowering drugs must to have proven $\mathrm{CV}$ safety in cardiovascular outcome trials (CVOTs) with major cardiovascular events (MACE) as primary outcome as a prerequisite for approval.

After initial neutral results of safety studies for MACE [23-27] with dipeptidyl peptidase 4 (DPP4) inhibitors and some glucagon-like peptide 1 receptor agonists (GLP-1RAs), recently published CVOTs, i.e. EMPA-REG with the sodium-glucose cotransporter 2 (SGLT2) inhibitor empagliflozin [28], CANVAS and CREDENCE with canagliflozin $[29,30]$, DECLARE with dapagliflozin [31], LEADER with the GLP1RA liraglutide [32], SUSTAIN-6 with semaglutide [33], HARMONY-OUTCOMES with albiglutide [34] and REWIND with dulaglutide [35], have substantially changed the recommended stepwise approach to manage glycaemic control in type 2 diabetes [36, 37]. Insulin at this stage is only recommended as part of triple therapy or even only if triple therapy fails as "last option" after an initial therapeutic trial with a GLP-1RA. Furthermore, in current recommendations the dysglycaemic level for initiation of insulin therapy was set to a glycated haemoglobin $\left(\mathrm{HbA}_{1 \mathrm{c}}\right)$ target of $10 \%$ or $11 \%$, or a fasting blood glucose in older individuals and people at risk of hypoglycaemia of $300 \mathrm{mg} / \mathrm{dL}$ [38]. These recommendations, however, may result in an inadequate delay of timely insulin treatment with harmful effects not only on metabolic memory [39] but also on quality of life as well as the mental and physical fitness of patients. Moreover, with clear evidence for CV and renal benefit of SGLT2 inhibitors and GLP-1RAs, the European Society of Cardiology (ESC) 2019 guidelines recommend these drugs even as first-line treatment before metformin in patients with atherosclerotic vascular disease, heart failure and chronic kidney disease (CKD) [40]. Thus, at present, we envision a substantial risk that in the light of favourable results of CVOTs with SGLT2 inhibitors and GLP-1RAs in special populations with high $\mathrm{CV}$ risk, clinical inertia with respect to improving glucose control by insulin therapy may be facilitated. Thereby, the notion that good glucose control early in diabetes history with timely initiation of insulin can protect pancreatic $\beta$-cells and reduce the development of microangiopathy and diabetes-related complications must not be neglected. In this overview, we will analyse the risk/benefit balance of timely insulin in type 2 diabetes therapy derived from appropriate trials. This approach aims to provide a rationale for individualised insulin therapy in conjunction with the American Diabetes Association/European Association for the Study of Diabetes (ADA/EASD) consensus recommendations of 2018 (updated in 2019 [41]) and the ESC guidelines in 2019 $[38,40,42]$.

This article is based on previously conducted studies and does not contain any studies with human participants or animals performed by any of the authors.

\section{RATIONALE FOR TIMELY INSULIN TREATMENT}

As a result of the progressive nature of type 2 diabetes, many patients will eventually become insulin-dependent [43-45]. Neither the latest guidelines for anti-hyperglycaemic treatment of patients with type 2 diabetes nor recent other literature exactly defines the threshold to initiate insulin therapy in type 2 diabetes. In contrast, in all available guidelines and recommendations, the necessity for insulin therapy is defined by the inability to reach an individualised $\mathrm{HbA}_{1 \mathrm{c}}$ goal. Real-world data show that individual $\mathrm{HbA}_{1 \mathrm{c}}$ targets are not achieved in the majority of cases, especially when insulin treatment is delayed [45]. Moreover, according to real-world studies, insulintreated patients also do not reach individual glycaemic targets in many cases [46]. Thus, the potential of a start with insulin therapy in a timely manner should be rethought strategically.

Most of the evidence implies that timely insulin treatment has two major advantages for glycaemic control: (1) potent glucose-lowering 
efficacy, and timely treatment may protect pancreatic $\beta$-cells, thereby providing an insulinsparing strategy in the long run (2) which may pose lower risk of hypoglycaemia and weight gain [47].

An $\mathrm{HbA}_{1 \mathrm{c}}$ below $7 \%$ is the accepted gold standard for diabetes control. In addition, stable glucose homeostasis avoiding peaks and hypoglycaemic episodes has been demonstrated to be of important clinical relevance, not least in relation to risk of $\mathrm{CV}$ and cerebral complications, as well as for fitness in daily life.

Several oral antidiabetic drugs (OADs) have proven high glucose-lowering potency, being in some randomised clinical trials equivalent to the efficacy of insulin therapy [42]. In these studies, $\mathrm{HbA}_{1 \mathrm{c}}$ baseline values were between $7.5 \%$ and $9.1 \%$. In this range, GLP-1RAs in particular showed comparable results to insulin with a similar percentage of participants achieving individualised goals [48]. Nevertheless, it should be reconciled that most of these randomised trials lasted only 26 weeks, only few with extension to 52 weeks. The 26 -week trials frequently allowed not enough time to titrate insulin properly. In some trials comparing therapy with insulin vs. GLP-1RAs, maximum $\mathrm{HbA}_{1 \mathrm{c}}$ reduction had been reached after 12 or 18 weeks with the highest dosage of GLP-1RA. In parallel, insulin titration was stopped per protocol at 20 or $24 \mathrm{IU}$ followed by $\mathrm{HbA}_{1 \mathrm{c}}$ worsening in the weeks thereafter [49-51]. Comparable results were seen within the ORIGIN trial with other newer glucose-lowering drugs (e.g. DDP4 or SGLT2 inhibitors) [12]. Avogaro et al. [52] showed in a meta-analysis of DPP4 inhibitors an apparently accepted mean increase in $\mathrm{HbA}_{1 \mathrm{c}}$ of $0.22 \%$ after 52 weeks of usage. Long-term loss of glycaemic control of $0.30 \%$ over 4 years of treatment was observed with dapagliflozin [53]. A declining efficacy for SGLT2 inhibitors was also observed in a metaanalysis by Monami et al. [54] over 104 weeks, but these compounds were more effective than DDP4 inhibitors over this period. According to another meta-analysis, $\mathrm{HbA}_{1 \mathrm{c}}$ reduction was smaller when DDP4 inhibitors were used in monotherapy as opposed to a combination with metformin [55]. All these trials revealed decreasing efficacy of these compounds over time, due to "progression" of $\beta$-cell failure.

Only intensive insulin treatment is able to reliably correct hyperglycaemia and lipotoxicity within 1 to 2 days of treatment [10]. This has been shown for insulin glargine and insulin degludec. Furthermore, insulin glargine has been demonstrated to keep glucose to a near normal range over an extended period of more than 6 years [56]. While there are no specific head-to-head trials testing long-term efficacy and durability of insulin versus SGLT2 inhibitors and/or GLP-1RAs, it has been demonstrated that both insulin glargine and insulin degludec are able to constantly maintain glycaemic control over extended periods of more than 3 years in the DEVOTE, BRIGHT and CONCLUDE trials [57-59].

When looking at possible pancreatic $\beta$-cell protective effects of insulin, it is important to distinguish between $\beta$-cell function, i.e. insulin biosynthesis and secretion, and $\beta$-cell mass. While most of the data on pancreatic $\beta$-cell mass are derived from in vitro or animal studies, evidence on $\beta$-cell function is derived from surrogate measures e.g. in glucose clamp analyses or mathematical calculations (homoeostatic model assessment, HOMA).

Berard et al. [60] estimated that a minimum of $15 \%$ or $20 \%$ of pancreatic $\beta$-cell function is needed for an adequate glucose-lowering effect of most of the OADs. However, it does not seem to be reasonable to wait until $\beta$-cell failure exists to such a high degree, especially when some oral drugs lose more and more effectiveness with declining $\beta$-cell function. Although some OADs have shown the ability to maintain or even improve $\beta$-cell function and critical loss of $\beta$-cell mass [61], many of them depend on preserved $\beta$-cell function, which becomes an issue in later stages of type 2 diabetes. In contrast, insulin can be used at any stage in type 2 diabetes management, independent of more or less insufficient $\beta$-cell function. Studies with longterm insulin use have demonstrated very stable glycaemic levels at target, indirectly suggesting that insulin therapy is the most appropriate way to induce pancreatic $\beta$-cell rest as an important precondition of long-term preserved endogenous insulin biosynthesis $[12,62]$. In a 
meta-analysis of short-term intensive insulin therapy, Kramer et al. [63] calculated a mean increase in $\beta$-cell function (HOMA-B) of 1.13 (95\% confidence interval [CI] 1.02-1.25) and a decrease in insulin resistance (HOMA-IR) of $0.57(95 \% \mathrm{CI}-0.84$ to 0.29$)$ as an insulin effect. Remission of diabetes was still observed in $42 \%$ of patients after 2 years.

Particularly in early stages, but also up to 5 years after manifestation, pathophysiological important improvements of $\beta$-cell function and hepatic insulin resistance were shown under insulin therapy owing to rapid improvement of gluco- and lipotoxicity [11, 64, 65]. Insulin supports improvement of physiological pancreatic $\beta$-cell function ("increased readily releasable insulin pool" close to the cell membrane of the $\beta$-cell) [65]. In addition, many studies demonstrated the interrelation of low residual $\beta$-cell function as a driver of glucotoxicity [66] and elevated hypoglycaemic risk. Thus, progression of type 2 diabetes may be associated with higher risk of $\mathrm{SH}$. The higher the $\beta$-cell reserve (C-peptide) is, the lower the risk of hypoglycaemia. Furthermore, $\mathrm{SH}$ and weight gain are more expressed when starting insulin (too) late or at high $\mathrm{HbA}_{1 \mathrm{c}}$ levels [67]. Here, timely combination of insulin with SGLT2 inhibitors or GLP-1RAs may be considered $[12,68,69]$.

\section{RESULTS OF CVOTS}

Cardiovascular disease (CVD) and CKD are the major causes of morbidity and mortality in patients with type 2 diabetes. Therefore, in times of positive outcome trials with SGLT2 inhibitors and GLP-1RAs, risk/benefit balance of insulin treatment needs to be re-evaluated. There are only four studies available that compare insulin with other glucose-lowering drugs. Moreover, most of these trials have been performed many years ago. Therefore, it is important to note that diabetes standards of care have changed substantially in the decades since their publication. While results cannot be easily translated to modern clinical practice, trial results still give important insights into the $\mathrm{CV}$ effects of insulin versus other glucose-lowering substances.

\section{UGDP}

The UGDP (University Group Diabetes Program) was the first randomised clinical trial that compared CV outcome of insulin in a fixed dose insulin regimen, variable dose insulin and a diet plus oral placebo regimen in over 600 patients with a follow-up time of 13 years. No difference was found in the incidence of myocardial infarction, CV and all-cause mortality between insulin arms vs. the oral placebo group. However, this early trial had critical shortcomings due to inadequate statistical power, insignificant differences in glucose control levels and, from the perspective of today, usage of inappropriate insulin regimens $[70,71]$.

\section{UKPDS}

The UKPDS (United Kingdom Prospective Diabetes Study) was a landmark study evaluating benefits of intensive glucose control with the usage of insulin for micro- and macrovascular disease and mortality in newly diagnosed, drugnaive patients with type 2 diabetes [72]. Intensive treatment was significantly more effective to reduce $\mathrm{HbA}_{1 \mathrm{c}}-7.0 \%$ vs. $7.9 \%$ after 10 years. There was a strong trend for the reduction of the risk of myocardial infarction at the end of the study with $21 \%$ reduction with intensified treatment (insulin or sulfonylurea; $P=0.057$ ) whereas no significant difference was observed in CV events and all-cause mortality.

The "Legacy" analysis 10 years after the end of intervention, however, showed a clear benefit of intensified treatment with respect to $\mathrm{CV}$ outcome and mortality independent of quality of $\mathrm{HbA}_{1 \mathrm{c}}$ control after intervention. The relative risk reduction of non-fatal myocardial infarction was $15 \%(P=0.01)$, that for death related to diabetes was $17 \%(P=0.01)$ and that for allcause mortality was $13 \%(P=0.007)$ [73].

These data prove, on the one hand, that intensified treatment including insulin has a clear preventive effect on MACE and mortality in patients with newly diagnosed type 2 
diabetes in the long run. On the other hand, the "Legacy" study showed that it takes decades to demonstrate that intensified glucose-lowering treatment including insulin can change the medical history of diabetes complications. The long lag-time of benefit of intensified diabetes control with insulin for $\mathrm{CV}$ complications reveals a striking analogy to the Diabetes Control and Complications Trial (DCCT) in patients with type 1 diabetes. Here, a significant reduction of MACE was observed only after 17 years [74]. During 30 years of follow-up, 32\% reduction in MACE was achieved $(P=0.007)$. Of note, the lower $\mathrm{HbA}_{1 \mathrm{c}}$ level in the DCCT/ Epidemiology of Diabetes Interventions and Complications (EDIC) accounted for more than 90\% of the prevention effect on CV risk. Other risk factors were hypertension and albuminuria [75].

\section{DIGAMI}

The randomised trial of insulin-glucose infusion followed by subcutaneous insulin treatment in patients with diabetes and acute myocardial infarction (DIGAMI 1) tested whether intensive insulin treatment in comparison to standard of care can improve mortality at year 1 after an acute coronary event. In 19 Swedish clinics, a group of 620 patients was randomly allocated to multidose insulin treatment or conventional treatment. The 1-year mortality rate was $8.6 \%$ in the insulin group vs. $18.0 \%$ in the control group; relative reduction was $52 \%, P=0.020$ [76]. Subsequently, however, these positive results could not be confirmed in a European trial with a similar protocol-DIGAMI 2-including 1253 patients. At the end of DIGAMI 2, $\mathrm{HbA}_{1 \mathrm{c}}$ was in the same range for patients in both standard of care and the group with insulin infusion followed by insulin-based glucose control. Mortality did not differ between the groups at the end of the study [77]. Thus, DIGAMI 2 did not show a benefit in favour of long-term insulin treatment in patients with acute myocardial infarction as compared to standard of care. This study, however, had some critical shortcomings: (1) $\mathrm{HbA}_{1 \mathrm{c}}$ and glucose targets were not achieved over the study period; (2) in contrast to
DIGAMI 1, diabetologists were not included in the treatment at the acute coronary care unit and during follow-up.

In 2014, the 20-year mortality results of DIGAMI 1 were published [78]. The mean follow-up time in this intention-to-treat analysis was 7.3 years. Median survival time was 7.0 years (interquartile range [IQR] 1.8-12.4) with insulin vs. 4.7 years (IQR 1.0-11.4) in the standard group $(P=0.027)$. Overall, insulin treatment increased survival by 2.3 years. The authors concluded that intensified glucose control with insulin in patients with previous myocardial infarction had a long-lasting effect on survival after acute myocardial infarction.

\section{ORIGIN}

ORIGIN (Outcome Reduction with an Initial Glargine Intervention) was a landmark trial testing CV outcome and preventive potential of early near to normal blood glucose control with a basal insulin analogue-insulin glargine. This long-term prospective, randomised trial included 12,537 subjects with high CV risk, of these $12 \%$ with pre-diabetes and $88 \%$ with a short diabetes duration. Insulin glargine treatment was targeted to fasting blood glucose level $<5.3 \mathrm{mmol} / \mathrm{L}(<94 \mathrm{mg} / \mathrm{dL})$. The control group was treated according to national guidelines to reach an $\mathrm{HbA}_{1 \mathrm{c}}<7.0 \%$. Follow-up time was 6.2 years. The primary outcome for MACE was neutral. The same applied for the secondary objectives heart failure and all-cause mortality. There was no difference in the incidence of cancer. At the end of the ORIGIN trial the insulin glargine dosage remained below $0.4 \mathrm{IU} /$ $\mathrm{kg}$ body weight with less OADs and intensified conventional therapy (ICT) needed than in the standard of care group [12, 79]. Adverse effects of insulin treatment were moderate weight gain $(+1.6 \mathrm{~kg})$. Severe hypoglycaemic episodes occurred in $5.7 \%$ of patients with insulin vs. $1.8 \%$ with standard of care. Severe hypoglycaemic episodes were associated with a higher risk of MACE (hazard ratio [HR] 1.71) and arrhythmic death (HR 1.77). However, in the case of insulin treatment the HR was significantly lower for the secondary outcome MACE 
and arrhythmic death as with standard of care. This positive effect of insulin persisted after adjustment for covariates such as sulfonylurea comedication. The authors discussed whether this protective effect of insulin is due to better myocardial blood flow or metabolic effects of insulin [80]. Moreover, treatment with insulin glargine in patients with pre-diabetes significantly delayed the progression to manifest diabetes, suggesting a protective "diseasemodifying" potential of insulin treatment in this early stage of diabetes history [80].

Protective effects of insulin pre-treatment were also reported for patients with hypoglycaemia at acute coronary units in the USA [81]. Hypoglycaemia was associated with an odds ratio of 2.32 in patients not treated with insulin. Iatrogenic hypoglycaemia was associated with a mortality of $18.4 \%$ vs. hypoglycaemia in association with insulin treatment of $9.2 \%$. The authors concluded that hypoglycaemia may represent a marker for excessive mortality risk, but insulin might have no causal relationship, but even could improve prognosis of $\mathrm{SH}$. This is supported by acute and late results of the DIGAMI 1 trial $[76,78]$, and secondary analyses of the ORGIN trial [80].

\section{PREVENTION OF MICROVASCULAR COMPLICATIONS WITH INSULIN TREATMENT}

With significant progress in the prevention of $\mathrm{CV}$ disease and overall increase in life expectancy of patients with type 2 diabetes, microvascular complications and other diabetes-related diseases become more and more prominent determinants of the fate of people with long-term diabetes. As shown by Bergenstal and colleagues, in the post-DCCT area reaching $\mathrm{HbA}_{1 \mathrm{c}} \leq 7.0 \%$ was associated with an impressive decline in MACE but less impressive decline in severe kidney disease [82]. Unfortunately, among people with long-term type 2 diabetes, treatment "not-to-target" frequently prevails [83]. Even worse, to minimise potential adverse effects of insulin (hypoglycaemia and weight gain), in CVOTs with intensified glucose control treatment with insulin was targeted to inadequate $\mathrm{HbA}_{1 \mathrm{c}}$ levels (> 8-10\%), particularly in older patients.

There exists, however, consistent evidence from CVOTs with neutral outcome for primary objectives (MACE) that $\mathrm{HbA}_{1 \mathrm{c}}$ is a strong and independent predictor for microvascular disease. In the UKPDS, intensified treatment with insulin had a significant effect on microvessel disease with a close relationship between $\mathrm{HbA}_{1 \mathrm{c}}$ and retinopathy down to $\mathrm{HbA}_{1 \mathrm{c}}<6 \%$ after 10 years of follow-up [72].

Of note, in the UKPDS early addition of insulin to oral treatment reduced the risk of complications [84]. The landmark study of benefit of early and timely insulin treatmentORIGIN-demonstrated a significant reduction of CKD and retinopathy in participants with $\mathrm{HbA}_{1 \mathrm{c}} \geq 6.4 \%$ at baseline. The HR of composite hard endpoints of kidney and eye disease was 0.90 (95\% CI 0.81-0.99). The strongest effect was observed on reduction of microalbuminuria [85]. With respect to quality of life, it is remarkable that in the ORIGIN study basal insulin glargine also improved muscular strength in the handgrip test and erectile dysfunction [86].

\section{RELEVANCE OF POTENTIAL ADVERSE EFFECTS OF INSULIN TREATMENT}

Safety and quality of life are major issues to be considered at initiation of insulin treatment [87]. Hypoglycaemia and weight gain are serious adverse effects of any glucose-lowering therapy addressed in recently published guidelines and treatment recommendations. Interestingly, prevalence and harmful consequences of hypoglycaemic events during glucose-lowering treatment with insulin seem to depend on several factors, and should be appraised also in the context of improvements in glycaemia and comedications. For example, it was demonstrated very early that weight gain can be attenuated if metformin is used or continued when initiating basal insulin [88]. Further, the time point of initiation in medical history of diabetes is one of the best-known variables especially when insulin was used in randomised 
clinical trials by heterogeneous subgroups of patients with type 2 diabetes. In the INSIGHT trial, starting at 7.6 years of diabetes duration, the $\mathrm{HbA}_{1 \mathrm{c}}$ reduction was $-0.3 \%(P=0.0007$, $8.6 \%$ at baseline). There was, however, no difference in hypoglycaemic events as compared to treatment with an additional OAD [89]. In the TULIP study with 10 years of diabetes duration at baseline, $\mathrm{HbA}_{1 \mathrm{c}}$ could be lowered using insulin glargine by $-0.8 \pm 0.7 \%$ (from $7.6 \pm 0.3 \%$ ), but resulted in $20.3 \%$ more patients with symptomatic hypoglycaemia and weight gain of $+1.89 \mathrm{~kg}$ in the insulin arm. The LANMET trial showed for patients with 9 years of type 2 diabetes a reduction in $\mathrm{HbA}_{1 \mathrm{c}}$ of $-2.4 \%$ (from $9.6 \%$ at baseline) with 5.4 hypoglycaemic episodes per patient year and a weight gain of $+2.6 \pm 0.6 \mathrm{~kg}$. Of importance, obese patients with insulin resistance frequently needed insulin dosages of more than $100 \mathrm{IU} /$ day (so-called insulin failures) [90, 91].

Evidence for fewer hypoglycaemic drug events and less weight gain if insulinisation starts earlier than later in progression of type 2 diabetes also comes from real-world data. In the EARLY trial, patients with type 2 diabetes and failure in OAD therapy who started basal insulin within 5 years after diagnosis had a weight difference of $-0.4 \mathrm{~kg}$ as compared to those with diagnosis 5 years or more before [68]. Another non-interventional longitudinal study on insulinisation revealed that the mean weight increase of $+1.78 \mathrm{~kg}$ after 1 year was highly dependent on baseline $\mathrm{HbA}_{1 \mathrm{c}}$ and insulin dosage needed to improve glycaemic control [92, 93]. Many studies show the highest weight gain among insulin therapies with premix formulations [94-96]. By contrast, Lingvay et al. [97] found a higher weight gain with triple OAD therapy of $+7.15 \mathrm{~kg}$ vs. $+4.5 \mathrm{~kg}$ premix insulin twice a day.

Severe hypoglycaemic episodes are serious adverse events of inappropriate insulin treatment. They are associated with increased risk of $\mathrm{CV}$ complications, heart failure, arrhythmias and mortality [80, 98-103]. However, a causal relationship and the relevance of $\mathrm{SH}$ for MACE is a matter of debate. Of note, the DCCT, a landmark trial in patients with type 1 diabetes that evaluated the effect of intensified insulin treatment over 7 years on micro- and macroangiopathy, showed that better $\mathrm{HbA}_{1 \mathrm{c}}$ control with more insulin resulted in higher incidence of $\mathrm{SH}$, but achieved a significant reduction in CV [104] and all-cause mortality [105] at 30 years follow-up. The DEVOTE study was a CV safety study comparing basal insulin glargine vs. basal insulin degludec in a high-risk type 2 diabetes cohort. While significantly fewer SHs were registered with degludec in comparison to the glargine arm (4.9 vs. 6.6), the rates of MACE and overall serious adverse events (SAEs) were equal between both groups. Thus, while $\mathrm{SH}$ has a non-significant causal relationship, if any, to CV complications and death, it represents an SAE that labels a very high-risk group for MACE, arrhythmias and cancer. Nevertheless, the question remains whether patients with type 2 diabetes treated with insulin may be exposed to higher risk if $\mathrm{SH}$ happens. A nationwide registry study in Sweden compared second-line addition of insulin to metformin vs. DPP4 inhibitors during 2007 and 2014. Objectives were incidence of CVD, mortality and hypoglycaemia. Insulin compared to DPP4 inhibitors was associated with higher risk of mortality, CVD and SH (HR 1.69, 1.39, 4.35, respectively). The increased HR persisted after adjustment by propensity score matching [106]. Zhuang et al. [107] performed a meta-analysis including 170 trials with all novel glucose-lowering drugs and a total of 166,371 international participants with MACE, all-cause mortality and hypoglycaemia as objectives. In this largest database of controlled studies with sulfonylurea as reference, SGLT2 inhibitors, insulin, GLP1RA and DPP4 inhibitors were superior with respect to MACE, whereas SGLT2 inhibitors and insulin were better for mortality outcome. Of importance, MACE and all-cause mortality were associated with SH risk.

Thus, by extrapolation, $\mathrm{SH}$ is a serious risk factor for MACE, heart failure, cardiac arrhythmias and overall mortality with a bidirectional relationship. Inappropriate insulin treatment is associated with an odds ratio of $2-3$ for $\mathrm{SH}$. However, there is no evidence for a specific risk associated with timely and adequately titrated insulin treatment. 


\section{CLINICAL INDICATIONS FOR TIMELY INSULIN INITIATION}

\section{Early in Diabetes History with Clinical Symptoms}

ADA/EASD 2018 guidelines describe three clinical situations where insulin therapy may be considered [38, 108].

1. In case of established oral dual or triple therapy, basal insulin can be combined with a GLP-1RA or basal/prandial insulin, if $\mathrm{HbA}_{1 \mathrm{c}}$ is $>10 \%$, or $>2 \%$ above individual target. Furthermore, initial insulin treatment may be considered in the case of an $\mathrm{HbA}_{1 \mathrm{c}}>11 \%$ with symptoms of catabolism and sarcopenia. However, we ought to consider that such a high $\mathrm{HbA}_{1 \mathrm{c}}$ threshold may very well amplify the already prevailing inertia to start insulin. Depending on the pre-existing clinical picture including diabetes-related complications, insulin is sometimes also beneficial for patients with lower $\mathrm{HbA}_{1 \mathrm{c}}$ values. Therefore, in Table 1 we suggest recommendations for timely initiation of insulin therapy. By extrapolation, the authors also recommend to start insulin in any disease stage if the recommended target cannot be reached timely with other treatment options.

2. In patients with newly manifested diabetes with symptoms and high glucose toxicity, insulin is sufficient to quickly control blood glucose. Treatment of severely decompensated patients with clinical symptoms, dehydration, ketoacidosis and acute infections with intensified insulin therapy at the time of diagnosis has been good clinical practice for decades. The question of early insulin therapy for the protection of $\beta$-cells and the chance of a possible remission has received much attention over the past decade $[6,7,109-112]$. Several studies in patients with severe hyperglycaemia (starting with an $\mathrm{HbA}_{1 \mathrm{c}}>9 \%$ ) have shown that initial, intensive insulin treatment under inpatient conditions can result in longlasting remission after discontinuation of insulin therapy $[8,9,112]$. Li et al. [6] treated 138 newly diagnosed patients with fasting plasma glucose $>11.1 \mathrm{mmol} / \mathrm{L}$ (> $200 \mathrm{mg} / \mathrm{dL}$ ) in hospital for 2 weeks with continuous insulin infusion until normoglycaemia, which was achieved in 126 patients within 6 days. Thereafter, the therapy was exclusively with intensified lifestyle intervention. After 2 years, $42 \%$ of patients were still in remission. This unexpectedly high rate of non-progression with respect to remission was confirmed by several larger controlled studies from China [6, 7, 10], which were summarised in a review by Raz and Mosenzon [111]. In 2008, Weng et al. published the first large randomised trial of short-term, intensified insulin therapy with continuous subcutaneous insulin infusion (CSII) or multiple doses of insulin (MDI) and OADs as active comparator groups. Fasting plasma glucose of $7-16.7 \mathrm{mmol} / \mathrm{L}$ (126-300 mg/dL) was an inclusion criterion. Depending on the body mass index (BMI) of the patients, metformin or gliclazide was used as OAD. Normoglycaemia was achieved in patients with CSII after $4.0 \pm 2.5$ days $(97.1 \%)$, in MDI after $5.6 \pm 3.8(95.2 \%)$ and in OAD after $9.3 \pm 5.3$ days $(83.5 \%)$. Thereafter, the drug therapy was discontinued. One year after CSII , MDI and OAD 51.1\%, 44.9\% and $26.7 \%$ of the study participants were in remission, respectively. Of note, recovery of acute insulin response could only be demonstrated in patients with insulin therapy, while $\beta$-cell function in the OAD group had worsened [7].

3. In patients with severe insulin deficit, as substantiated e.g. by high postprandial glucose excursions and microvessel disease at diagnosis, there may be a preference for insulin. Effectiveness of insulin is highly dependent on its appropriate use, patient selection and training. Adjustment of dose for changes in diet, activity or weight are of utmost importance, as is titration to acceptable, safe glucose targets. Formulations of intermediate- and long-acting insulin have different durations of action and risks of hypoglycaemia. Inconvenience, deficits of education to titrate insulin dosage and costs 
Table 1 Patient-centred indications of timely initiation of insulin treatment

Subgroups with severe insulin deficit (majority young and lean)

Severe autoimmune diabetes/LADA with antibodies (SAID)

Severe insulin deficit (SIDD)

Early manifestation of diabetes-related complications (retinopathy, nephropathy) and $\mathrm{HbA}_{1 \mathrm{c}}$ out of target $(>6.5 \%$ to

$<7.5 \%$ to $8 \%$ ) despite dual or triple therapy with OADs and GLP-1 RAs

Increase of $\mathrm{HbA}_{1 \mathrm{c}}$ above target within 6 months despite dual and triple combinations

Seniors with sarcopenia, cachexia and chronic infections

Symptoms of "high sugar" (weakness, infections, dermatological problems, erectile dysfunction, nycturia)

of self-monitoring blood glucose represent frequent causes for the inertia to start insulin described above. A European study on compliance factors with insulin treatment revealed that a positive attitude of diabetes educators was the most important determinant for long-term adherence to insulin treatment [87].

\section{Within the Framework of Patient-Centred Treatment (2020)}

The ADA/EASD consensus statement 2018 on treatment of hyperglycaemia in type 2 diabetes proposed a patient-centred approach [38]. Now, different patient groups are lumped together on the basis of their clinical phenotype: patients in a first group with established CVD, heart failure or CKD; a second group with a need to minimise hypoglycaemia; a third group with a need to minimise weight gain or promote weight loss; and a fourth group where treatment costs are a major issue. This strategy attempts to guide a more tailored, individualised treatment in a way that specific patient groups are defined on the basis of their clinical phenotypes and needs. Nevertheless, this consensus has some clinical shortfalls. There is a CVOT and medication-driven key focus on CVD, heart failure and $\mathrm{CKD}$, but this group of patients includes not more than $20 \%$ of the overall diabetic population. A real individualised approach, therefore, should not only consider risk of CVD, heart failure, CKD, risk of hypoglycaemia, weight and costs but also additional pathophysiological characteristics (Table 1). Such an approach was followed by the group of Ahlqvist and colleagues [44] who linked six factors, namely glutamate decarboxylase antibodies, age at diagnosis, $\mathrm{BMI}, \mathrm{HbA}_{1 \mathrm{c}}$, and HOMA 2 estimates of $\beta$-cell function and insulin resistance, to define six clusters which were then correlated with the development of longterm complications. These baseline characteristics can guide individual approaches of insulin substitution in addition to the ADA/EASD consensus statement. Some of the identified clusters, for example, show a more rapid need for insulinisation than others as a result of endogenous insulin deficiency, a fact which will lead to different treatment algorithms based on pathophysiological backgrounds in the future.

\section{SPECIAL POPULATIONS (ELDERLY, FRAILTY)}

\section{Insulin Treatment in Older Patients}

Nowadays, the vast majority of people with type 2 diabetes worldwide are older than 65 years [113]. There are two major developments in demography causing a further huge increase of elderly patients with type 2 diabetes: (1) independent of diabetes, rapidly rising numbers of old people in developed as well as in developing countries along with a gain of life expectancy of about 10 years in the generation of baby boomers. (2) With increasing quality of outcomes of diabetes treatment and control of 
major CV risk factors as well as better treatment of CV complications, life expectancy of people with diabetes is approaching that of those without diabetes.

This development in demography is even more dramatic in Germany with one of the oldest populations worldwide. With a population of ca. 84 million inhabitants, in Germany about 17 million people are at least 65 years old, a number expected to increase to 22 million in 2070 , with 3 million people older than 65 years old suffering from diabetes mellitus [114]. Therefore, in recent years national and international boards have published recommendations and guidelines for medical treatment of older people with type 2 diabetes [108, 114, 115]. These guidelines collectively emphasise that older people are a very heterogeneous group with enormous differences in physical and mental fitness, comorbidities and social environment. Thus, an individual of 70 years may have a life expectancy of 2 or more than 20 years. Therefore, the treatment goal and a patient's expectations may be very different. This requires an even more individualised approach for the use of glucose-lowering drugs.

In old patients, two traits of the metabolic syndrome are of particular importance for $\mathrm{CV}$ complications: hypertension and dyslipidaemia. Prevalence of hypertension in old patients is $70-80 \%$ [116]. On the other hand, being overweight with $\mathrm{BMI}<30 \mathrm{~kg} / \mathrm{m}^{2}$ is of no importance or even beneficial for survival [117]. In clinical practice, this should be considered as a guide for individualised glucose-lowering drug treatment. Obviously, for overweight, old patients drug-induced weight reduction has no apparent benefit for survival.

$\mathrm{SH}$ in old patients is associated with a high risk of brain damage, particularly in the very old with pre-existing cerebrovascular atherosclerosis. As shown in a large registry study in older patients with type 2 diabetes, the excess risk of dementia with two episodes of $\mathrm{SH}$ increased to an HR of 1.86 if adjusted for comorbidities [118]. Moreover, old patients have an increased incidence of $\mathrm{CV}$ complications and arrhythmias during SHs [119]. However, as shown in the ORIGIN study [85] and by an acute care unit study [81], insulin-treated patients have fewer complications and lower mortality in the case of SH.

\section{Frailty and Sarcopenia}

Frailty and sarcopenia are common companions in age that interact in a vicious cycle. Sarcopenia is an age-related decline in skeletal muscle mass, strength, quality and function. It is associated with insulin resistance, less physical activity and psychosocial problems. Sarcopenia is an important risk factor for falls and fractures and plays a key role in the loss of mobility and ability of self-care in daily life. Therefore, protection of muscle strength should be an essential part of good diabetes treatment. The exact mechanisms behind the development of sarcopenia are not quite clear, but it represents a multifactorial process leading to catabolism with a deficit in protein synthesis [119]. Insulin is a strong anabolic hormone that improves protein synthesis [120]. It was even misused for that property as a doping drug in high-performance sports and by body builders.

Sarcopenia can occur in two phenotypes: severe cachexia and obesity with inertia. Patients suffering from an insulin deficit have lower resistance against oxidative stress, lowgrade inflammation and chronic infections, conditions that by evidence can be improved by insulin substitution. Thus, increased risk of hypoglycaemia to result in catastrophic events in the elderly must be counterbalanced by negative consequences of undertreatment (Table 2). In patients with cachexia timely introduction of low-dose basal insulin was shown to be of benefit [120]. In contrast, these patients if free of severe kidney disease or clinical heart failure may have no benefit from metformin, SGLT2 inhibitors or GLP-1RAs that unfortunately reduce body weight in that population.

\section{Targets for Glucose Control in Older Patients}

The targets for $\mathrm{HbA}_{1 \mathrm{c}}$ and glucose need to be adapted to individual mental and physical fitness, comorbidities, comedications and socio- 
Table 2 Harmful consequences of delayed initiation of insulin therapy and undertreatment of hyperglycaemia

Increased risk of diabetes-related complications

Promoted sarcopenia and dizziness

Reduced physical and mental fitness

Reduced resistance against infections

Reduced libido and sexual potency

In elderly, risk of nycturia and incontinence

Progressive deficit in $\beta$-cell mass and function

Higher dosage of insulin needed with higher risk of severe hypoglycaemia

economic conditions. In 2018 the ADA [108], the German Diabetes Association (DDG) [114] and other national societies published updated recommendations and guidelines for treatment of seniors. These guidelines emphasise the importance of safety and practicability in advanced age. With respect to increased risk of complications associated with hypoglycaemia in the elderly and little if any effect on CVD, they all open the window for rather high targets of $\mathrm{HbA}_{1 \mathrm{c}}$ up to $\geq 9 \%$ or glucose control only if patients are symptomatic. As a consequence, the introduction of insulin in second and third step regimens should be preferred in cases that cannot be treated to these targets with triple OADs and GLP-1RAs [108, 114, 121].

In conclusion, appropriate insulin in the framework of individualised treatment is effective with an acceptable risk/benefit balance in older, multimorbid patients with type 2 diabetes. Patients with sarcopenia, chronic infections and cachexia are target subpopulations for carefully adjusted insulin treatment.

\section{COMBINATIONS WITH SGLT2 INHIBITORS AND GLP-1 RECEPTOR AGONISTS}

With level Ia evidence for CV and renal benefit of two novel glucose-lowering drug groups, SGLT2 inhibitors and GLP-1RAs, the ESC/EASD guidelines 2019 recommend these compounds as first-line therapy before metformin in patients with CVD and CKD [40]. At present and in the near future we will not see outcome data from controlled trials with triple and multiple combinations with insulin. Therefore, decisions on the use of insulin in the framework of multiple drug combinations must be based on phase III clinical trials sponsored by the pharmaceutical industry with respect to control of $\mathrm{HbA}_{1 \mathrm{c}}$ and provide safety as primary objectives, clinical experience, plausibility and eventually results from big data registries.

\section{Insulin in Combination with GLP-1RAs}

Initiation of insulin if GLP-1RA plus metformin treatment does not achieve targets is a rational approach that uses synergistic and complementary actions of this triad.

A systematic review of additional treatment of an existing basal insulin therapy with several GLP-1RAs (exenatide, liraglutide, lixisenatide, albiglutide) as most common in clinical trials [122] highlighted the advantages of these effective and safe combinations. Advantages were lower hypoglycaemic risk, reduction in insulin dosages and improvements in patient compliance. Quality of glycaemic control of a basal insulin plus GLP-1RA was comparable to an addition of titrated prandial insulin [123-125]. In favour of the GLP-1RA/insulin combination it should be taken into account that the GLP-1RA has pleiotropic effects on the heart, liver and adipose tissue [126, 127]. As compared to the addition of prandial insulin, a weight loss of $-5.66 \mathrm{~kg}$ was observed; and compared to other basal insulin combinations, a weight reduction of $-3.22 \mathrm{~kg}$ was observed. In a review and systemic meta-analysis, the 
reduction in relative risk of hypoglycaemic events by GLP-1RAs was - 33\% as compared to prandial insulin combinations [127]. The metaanalysis included 15 studies with a diabetes duration of 6.7-17.1 years (mean 12.2 years) and baseline $\mathrm{HbA}_{1 \mathrm{c}}$ values of $7.4-8.8 \%$ (mean $8.13 \%)$. The combination of basal insulin with a GLP-1RA "yielded a 92\% higher likelihood of achieving target $\mathrm{HbA}_{1 \mathrm{c}}$ of $7.0 \%$ or lower by the end of the intervention, as compared with other glucose-lowering treatments".

As mentioned above, only few studies evaluated the sequential addition of basal insulin to an insufficient GLP-1RA therapy [122]. The poorly controlled $\left(\mathrm{HbA}_{1 \mathrm{c}} \geq 7 \%\right)$ participants in the so-called Liraglutide-Detemir Study were uptitrated to the maximum liraglutide dosage of $1.8 \mathrm{mg}$ for 12 weeks and separated into responders $\left(61 \%, \mathrm{HbA}_{1 \mathrm{c}}<7 \%\right)$ and non-responders (39\%) which were still above the target [128]. The problem of unsolved response/non-response or persistency to GLP-1RAs is well known, not only from randomised clinical trials but also from daily clinical practice [129]. During the following period over 26 weeks, responders in the Liraglutide-Detemir Study were maintained on $1.8 \mathrm{mg}$ liraglutide, and to evaluate the additional effect of basal insulin, non-responders were randomised to be treated further with liraglutide $1.8 \mathrm{mg}$ or combined with basal insulin titrated according to label (end dosage $0.41 \mathrm{IU} / \mathrm{kg}$ ). The liraglutide nonresponders stayed stable in $\mathrm{HbA}_{1 \mathrm{c}}$, but the group with additional basal insulin reached a statistically significant efficacy difference of $-0.52 \%$ $\mathrm{HbA}_{1 \mathrm{c}}$. Interestingly, $\mathrm{HbA}_{1 \mathrm{c}}$ in the responder group increased from run-in to study end by $+0.2 \%$ and it was lowest at $-1.12 \%$ in total compared to $-1.13 \%$ in the combined treatment group (liraglutide + basal insulin). Thus, addition of basal insulin to liraglutide was effective to treat patients to target and was safe and well tolerated without SHs and weight gain. In an open-label trial with two basal insulins, the combination with the GLP-1RA exenatide and OADs was effective to achieve $\mathrm{HbA}_{1 \mathrm{c}}$ targets with low rates of symptomatic hypoglycaemic events and only minimal weight gain [130].

$\mathrm{HbA}_{1 \mathrm{c}}$ and glucose monitoring in clinical trials reveal an inherent tendency of an increase in $\mathrm{HbA}_{1 \mathrm{c}}$ after 6-8 months [50, 131-133]. Therefore, timely addition of insulin should be considered to protect pancreatic $\beta$-cells from gluco-lipotoxicity and exploit anabolic effects on musculature. As a consequence, flexible fixed ratio combinations of insulins with a GLP1RA have been developed: insulin glargine/ lixisenatide (iGlarLixi [134]) and insulin degludec/liraglutide (iDegLira [135]). With these fixed-ratio combinations, pen applications that require only one injection per day have been provided. Clinical studies with iGlarLixi compared with its single components have revealed better efficacy, safety and compliance with the fixed combinations $[134,136]$. Improved efficacy, safety and compliance were also shown for iDegLira vs. single components [137, 138]. By extrapolation, these new fixed combinations have several advantages: superiority for $\mathrm{HbA}_{1 \mathrm{c}}$ and post-prandial glucose control, lower risk of hypoglycaemia, less weight gain and better adherence to therapy [134, 138-140]. Furthermore, a reduced insulin dosage is required and care for frail patients may be simplified [141].

Another approach to rational, timely use of insulin in multiple combinations with incretins must be clinical experience in multimorbid patients. Table 1 gives clinical characteristics that indicate a priority of insulin substitution. Again, insulin has the advantage that dysglycaemia can be controlled flexibly within a short period of time. Only insulin has anabolic effects of benefit in frail, multimorbid individuals with sarcopenia. In international surveys we see a rapid increase in the prescription of new drugs $[142,143]$.

There are, however, large national differences in the introduction of GLP-1RAs and SGLT2 inhibitors within Europe. At the moment, we could not find reliable epidemiological data comparing outcome and adverse effects of multiple oral combinations with GLP$1 R A s$ vs. combination with insulin.

\section{Insulin in Combinations with SGLT2 Inhibitors}

SGLT2 inhibitors were the first novel class of glucose-lowering medications with level Ia 
evidence for prevention of MACE, heart failure and CKD [28, 30, 31]. Mechanistic studies reveal a complementary effect of insulin added to SGLT2 inhibitors [144] counteracting enhanced hepatic gluconeogenesis, and providing inhibition of lipolysis and prevention of ketosis [145]. Furthermore, insulin adds anabolic effects and reduces incidence of urogenital infections [146-150]. In a meta-analysis of seven phase III studies in insulin-treated patients, SGLT2 inhibitors caused an $\mathrm{HbA}_{1 \mathrm{c}}$ reduction of $0.56 \%$ and a reduction of body weight by $2.6 \mathrm{~kg}$ associated with 8.7 IU less insulin compared to placebo [151].

Similar reductions in $\mathrm{HbA}_{1 \mathrm{c}}$ (between $-0.6 \%$ and $-0.7 \%$ ) were shown for empagliflozin for the long period of 78 weeks in addition to an uncontrolled basal insulin therapy (glargine U100, detemir, NPH insulin) [151] with similar hypoglycaemic events in all groups including placebo. The main reductions occurred during the first 12 weeks and remained stable especially with the $25 \mathrm{mg}$ dose in the following 56 weeks owing to an almost stable basal insulin dosage ( -1.2 to $-0.5 \mathrm{IU}$ from baseline), whereas in the placebo group the insulin dosage rose up by $+5.5 \mathrm{IU}$. The advantage of adding SGLT2 inhibitors to basal insulin therapy vs. an ongoing monotherapy was recently confirmed in a meta-analysis by Monami et al. [54].

The risk of genital mycotic infections increases with the development of glucosuria. Clinical experience suggests that timely insulin addition with near to normal glucose control has preventive effects on genital candidiasis $[152,153]$.

There are no outcomes available on benefit of insulin when added to SGLT2 inhibitors plus metformin and/or other OADs. Thus, timely initiation in the framework of multiple combinations with SGLT2 inhibitors as first-line drug depends on pathophysiological and clinical reasoning of risk/benefit and not least the unmet needs of our patients.

In summary, while SGLT2 inhibitors and GLP-1RAs show strong evidence for early use, for combination therapy of insulin with SGLT2 inhibitors and/or GLP1-RAs, it is reasonable to recommend an early add-on of insulin to those drugs in order to get to target, improve longterm persistence on $\mathrm{HbA}_{1 \mathrm{c}}$ and reduce microvascular disease risk.

\section{CONCLUSIONS}

Type 2 diabetes is a progressive chronic disease with deficits in pancreatic $\beta$-cell function and insulin resistance in muscle, liver and adipose tissue as core defects together with low-grade inflammation. Gluco- and lipotoxicity have harmful effects on residual $\beta$-cell function and islet cell regeneration. Therefore, timely initiation of insulin to achieve near to normal glucose homeostasis and to control lipotoxicity and inflammation is an option at any time to protect $\beta$-cells and to avoid harmful remodelling of the metabolic memory. Insulin treatment, however, is a double edged sword that may have serious adverse effects such as hypoglycaemia and weight gain. Thus, an individualised approach to start insulin therapy is essential on the basis of risk/benefit balance.

In principle, we recommend two strategies for insulin use: (1) insulin (as first-line drug) at diagnosis of diabetes. The indication is severe hyperglycaemia with $\mathrm{HbA}_{1 \mathrm{c}} \geq 9-10 \%$ and subtypes with severe insulin deficit and clinical disease. This strategy is most effective to control gluco-lipotoxicity, favours revival of $\beta$-cell function, avoids harmful effects on metabolic memory and has a high rate of diabetes remission; (2) insulin as a combination with OADs and/or GLP-1RAs at the time when $\mathrm{HbA}_{1 \mathrm{c}}$ is out of target or the patient develops diabetes-related complications, or suffers from infections, sarcopenia etc. that benefit from the pleiotropic effects of insulin.

\section{ACKNOWLEDGEMENTS}

The content published herein represents the views and opinions of the various contributing authors and does not necessarily represent the views or opinion of Sanofi-Aventis Deutschland $\mathrm{GmbH}$ and/or its affiliates. 
Funding. Preparation of the manuscript and the Rapid Service Fee were funded by SanofiAventis Deutschland GmbH.

\section{Medical Writing and Editorial Assis-} tance. Medical writing and editorial support were provided by Dr. Antje Gasparic of Vitilis and paid for by Sanofi-Aventis Deutschland $\mathrm{GmbH}$.

Authorship. All named authors meet the International Committee of Medical Journal Editors (ICMJE) criteria for authorship for this article, take responsibility for the integrity of the work as a whole, and have given their approval for this version to be published.

Disclosures. Markolf Hanefeld: Boards: Sanofi SC for ORIGIN, Lilly SC for REWIND, AstraZeneca SC for EXSCEL; Lecture fees: Bayer, AstraZeneca, Lilly, Sanofi, Abbott, Novo Nordisk. Holger Fleischmann: former employee of Sanofi-Aventis Deutschland GmbH. Thorsten Siegmund: Boards: Abbott, Ascensia, AstraZeneca, Bayer, Boehringer Ingelheim, Lilly, Janssen, Medtronic, MSD, Novo Nordisk, Sanofi; Lecture fees: Abbott, Ascensia, AstraZeneca, Bayer, Berlin Chemie, Boehringer Ingelheim, Lilly, Medtronic, MSD, Novartis, Novo Nordisk, Sanofi. Jochen Seufert: Advisory board member Abbott, AstraZeneca, Boehringer Ingelheim, GI Dynamics, Janssen, LifeScan Mundipharma Novartis, Novo Nordisk, Sanofi. Speaker Abbott, AstraZeneca, Bayer, Berlin Chemie Boehringer Ingelheim, Bristol Myers Squibb, Janssen, Eli Lilly, Merck Sharp Dohme (MSD) MedScape Novartis, Novo Nordisk, Omniamed, Sanofi, Research support AstraZeneca, Boehringer Ingelheim, Bristol Myers Squibb, GI Dynamics, Intarcia Ipsen, Janssen, Novartis, Novo Nordisk, Sanofi, Ypsomed.

Compliance with Ethics Guidelines. This article is based on previously conducted studies and does not contain any studies with human participants or animals performed by any of the authors.

Open Access. This article is licensed under a Creative Commons Attribution-NonCommercial
4.0 International License, which permits any non-commercial use, sharing, adaptation, distribution and reproduction in any medium or format, as long as you give appropriate credit to the original author(s) and the source, provide a link to the Creative Commons licence, and indicate if changes were made. The images or other third party material in this article are included in the article's Creative Commons licence, unless indicated otherwise in a credit line to the material. If material is not included in the article's Creative Commons licence and your intended use is not permitted by statutory regulation or exceeds the permitted use, you will need to obtain permission directly from the copyright holder. To view a copy of this licence, visit http:// creativecommons.org/licenses/by-nc/4.0/.

\section{REFERENCES}

1. Adler AI, Neil HA, Manley SE, Holman RR, Turner RC. Hyperglycemia and hyperinsulinemia at diagnosis of diabetes and their association with subsequent cardiovascular disease in the United Kingdom prospective diabetes study (UKPDS 47). Am Heart J. 1999;138(5 Pt 1):S353-S359359.

2. Matveyenko AV, Butler PC. Relationship between beta-cell mass and diabetes onset. Diabetes Obes Metab. 2008;10(Suppl 4):23-31.

3. Owens DR. Clinical evidence for the earlier initiation of insulin therapy in type 2 diabetes. Diabetes Technol Ther. 2013;15(9):776-85.

4. Ceriello A. Hypothesis: the "metabolic memory", the new challenge of diabetes. Diabetes Res Clin Pract. 2009;86(Suppl 1):S2-6.

5. Meece J. Pancreatic islet dysfunction in type 2 diabetes: a rational target for incretin-based therapies. Curr Med Res Opin. 2007;23(4):933-44.

6. Li Y, Xu W, Liao Z, et al. Induction of long-term glycemic control in newly diagnosed type 2 diabetic patients is associated with improvement of beta-cell function. Diabetes Care. 2004;27(11):2597-602.

7. Weng J, Li Y, Xu W, et al. Effect of intensive insulin therapy on beta-cell function and glycaemic control in patients with newly diagnosed type 2 diabetes: a multicentre randomised parallel-group trial. Lancet. 2008;371(9626):1753-60. 
8. Ilkova H, Glaser B, Tunckale A, Bagriacik N, Cerasi E. Induction of long-term glycemic control in newly diagnosed type 2 diabetic patients by transient intensive insulin treatment. Diabetes Care. 1997;20(9):1353-6.

9. Park S, Choi SB. Induction of long-term normoglycemia without medication in Korean type 2 diabetes patients after continuous subcutaneous insulin infusion therapy. Diabetes Metab Res Rev. 2003;19(2):124-30.

10. Chen HS, Wu TE, Jap TS, Hsiao LC, Lee SH, Lin HD. Beneficial effects of insulin on glycemic control and beta-cell function in newly diagnosed type 2 diabetes with severe hyperglycemia after short-term intensive insulin therapy. Diabetes Care. 2008;31(10):1927-32.

11. Wajchenberg BL. Beta-cell failure in diabetes and preservation by clinical treatment. Endocr Rev. 2007;28(2):187-21818.

12. Origin Trial Investigators, Gerstein HC, Bosch J, et al. Basal insulin and cardiovascular and other outcomes in dysglycemia. $\mathrm{N}$ Engl J Med. 2012;367(4):319-28.

13. Alvarsson M, Sundkvist G, Lager I, et al. Beneficial effects of insulin versus sulphonylurea on insulin secretion and metabolic control in recently diagnosed type 2 diabetic patients. Diabetes Care. 2003;26(8):2231-7.

14. Pistrosch F, Kohler C, Schaper F, Landgraf W, Forst T, Hanefeld M. Effects of insulin glargine versus metformin on glycemic variability, microvascular and beta-cell function in early type 2 diabetes. Acta Diabetol. 2013;50(4):587-95.

15. Hanefeld MF, Fleischmann H, Liebl A, Siegmund T. Early or short-term insulin therapy in type 2 diabetes: significance and risk/benefit balance in the context of individualised therapy concepts. Diabetologie Stoffwechsel. 2019;14:45-55.

16. Kjems LL, Kirby BM, Welsh EM, et al. Decrease in beta-cell mass leads to impaired pulsatile insulin secretion, reduced postprandial hepatic insulin clearance, and relative hyperglucagonemia in the minipig. Diabetes. 2001;50(9):2001-122.

17. Christensen MB, Gaede P, Hommel E, Gotfredsen A, Norgaard K. Glycaemic variability and hypoglycaemia are associated with C-peptide levels in insulin-treated type 2 diabetes. Diabetes Metab. 2020;46(1):61-5.

18. Hope SV, Knight BA, Shields BM, et al. Random non-fasting C-peptide testing can identify patients with insulin-treated type 2 diabetes at high risk of hypoglycaemia. Diabetologia. 2018;61(1):66-74.
19. Monnier L, Hanefeld M, Schnell O, Colette C, Owens D. Insulin and atherosclerosis: how are they related? Diabetes Metab. 2013;39(2):111-7.

20. Gerstein HC, Jung H, Ryden L, et al. Effect of basal insulin glargine on first and recurrent episodes of heart failure hospitalization: the ORIGIN trial (Outcome Reduction With Initial Glargine Intervention). Circulation. 2018;137(1):88-90.

21. Scognamiglio R, Avogaro A, de Kreutzenberg SV, et al. Effects of treatment with sulfonylurea drugs or insulin on ischemia-induced myocardial dysfunction in type 2 diabetes. Diabetes. 2002;51(3): 808-12.

22. Scognamiglio R, Negut C, de Kreutzenberg SV, Tiengo A, Avogaro A. Effects of different insulin regimes on postprandial myocardial perfusion defects in type 2 diabetic patients. Diabetes Care. 2006;29(1):95-100.

23. Holman RR, Bethel MA, Mentz RJ, et al. Effects of once-weekly exenatide on cardiovascular outcomes in type 2 diabetes. $N$ Engl J Med. 2017;377(13): 1228-399.

24. Holman RR, Peterson ED. Sitagliptin and cardiovascular outcomes in type 2 diabetes. N Engl J Med. 2015;373(25):2479.

25. White WB, Cannon CP, Heller SR, et al. Alogliptin after acute coronary syndrome in patients with type 2 diabetes. N Engl J Med. 2013;369(14): 1327-35.

26. Scirica BM, Bhatt DL, Braunwald E, et al. Saxagliptin and cardiovascular outcomes in patients with type 2 diabetes mellitus. $\mathrm{N}$ Engl $\mathrm{J}$ Med. 2013;369(14):1317-26.

27. Pfeffer MA, Claggett B, Diaz R, et al. Lixisenatide in patients with type 2 diabetes and acute coronary syndrome. N Engl J Med. 2015;373(23):2247-57.

28. Zinman B, Wanner C, Lachin JM, et al. Empagliflozin, cardiovascular outcomes, and mortality in type 2 diabetes. N Engl J Med. 2015;373(22): 2117-288.

29. Perkovic V, Jardine MJ, Neal B, et al. Canagliflozin and renal outcomes in type 2 diabetes and nephropathy. N Engl J Med. 2019;380(24): 2295-306.

30. Mahaffey KW, Neal B, Perkovic V, et al. Canagliflozin for primary and secondary prevention of cardiovascular events: results from the CANVAS program (Canagliflozin Cardiovascular Assessment Study). Circulation. 2018;137(4):323-34. 
31. Wiviott SD, Raz I, Bonaca MP, et al. Dapagliflozin and cardiovascular outcomes in type 2 diabetes. N Engl J Med. 2019;380(4):347-57.

32. Marso SP, Daniels GH, Brown-Frandsen K, et al. Liraglutide and cardiovascular outcomes in type 2 diabetes. N Engl J Med. 2016;375(4):311-22.

33. Marso SP, Bain SC, Consoli A, et al. Semaglutide and cardiovascular outcomes in patients with type 2 diabetes. N Engl J Med. 2016;375(19):1834-44.

34. Hernandez AF, Green JB, Janmohamed S, et al. Albiglutide and cardiovascular outcomes in patients with type 2 diabetes and cardiovascular disease (Harmony Outcomes): a double-blind, randomised placebo-controlled trial. Lancet. 2018;392(10157): 1519-29.

35. Gerstein HC, Colhoun HM, Dagenais GR, et al. Dulaglutide and cardiovascular outcomes in type 2 diabetes (REWIND): a double-blind, randomised placebo-controlled trial. Lancet. 2019;394(10193): 121-30.

36. American Diabetes Association. 8. Pharmacologic approaches to glycemic treatment: standards of medical care in diabetes-2018. Diabetes Care. 2018;41(Suppl 1):S73-S85.

37. International Diabetes Federation. Global guideline for type 2 diabetes 2012. https://www.idf.org/elibrary/guidelines/79-global-guideline-for-type-2diabetes. Accessed 10 April 2017.

38. Davies MJ, D'Alessio DA, Fradkin J, et al. Management of hyperglycemia in type 2 diabetes, 2018. A consensus report by the American Diabetes Association (ADA) and the European Association for the Study of Diabetes (EASD). Diabetes Care. 2018;41(12):2669-701.

39. El-Osta A, Brasacchio D, Yao D, et al. Transient high glucose causes persistent epigenetic changes and altered gene expression during subsequent normoglycemia. J Exp Med. 2008;205(10):2409-17.

40. Cosentino F, Grant PJ, Aboyans V, et al. 2019 ESC guidelines on diabetes, pre-diabetes, and cardiovascular diseases developed in collaboration with the EASD. Eur Heart J. 2020;41(2):255-32323.

41. Buse JB, Wexler DJ, Tsapas A, et al. 2019 update to: management of hyperglycaemia in type 2 diabetes, 2018. A consensus report by the American Diabetes Association (ADA) and the European Association for the Study of Diabetes (EASD). Diabetologia. 2020;63(2):221-8.

42. Riddle MC, Gerstein HC, Holman RR, et al. A1C targets should be personalized to maximize benefits while limiting risks. Diabetes Care. 2018;41(6): 1121-4.

43. Riddle MC, Rosenstock J, Gerich J, Insulin Glargine Study I. The treat-to-target trial: randomized addition of glargine or human NPH insulin to oral therapy of type 2 diabetic patients. Diabetes Care. 2003;26(11):3080-6.

44. Ahlqvist E, Storm P, Karajamaki A, et al. Novel subgroups of adult-onset diabetes and their association with outcomes: a data-driven cluster analysis of six variables. Lancet Diabetes Endocrinol. 2018;6(5):361-9.

45. Fonseca V, Gill J, Zhou R, Leahy J. An analysis of early insulin glargine added to metformin with or without sulfonylurea: impact on glycaemic control and hypoglycaemia. Diabetes Obes Metab. 2011;13(9):814-22.

46. Seufert J, Fritsche A, Pscherer S, et al. Titration and optimization trial for the initiation of insulin glargine $100 \mathrm{U} / \mathrm{mL}$ in patients with inadequately controlled type 2 diabetes on oral antidiabetic drugs. Diabetes Obes Metab. 2019;21(2):439-43.

47. Garvey WT, Olefsky JM, Griffin J, Hamman RF, Kolterman OG. The effect of insulin treatment on insulin secretion and insulin action in type II diabetes mellitus. Diabetes. 1985;34(3):222-34.

48. Aziz MSA, Kahle M, Meier JJ, Nauck MA. A metaanalysis comparing clinical effects of short- or longacting GLP-1 receptor agonists versus insulin treatment from head-to-head studies in type 2 diabetic patients. Diabetes Obes Metab. 2017;19(2):216-27.

49. Heine RJ, Van Gaal LF, Johns D, et al. Exenatide versus insulin glargine in patients with suboptimally controlled type 2 diabetes: a randomized trial. Ann Intern Med. 2005;143(8):559-69.

50. Russell-Jones D, Vaag A, Schmitz O, et al. Liraglutide vs insulin glargine and placebo in combination with metformin and sulfonylurea therapy in type 2 diabetes mellitus (LEAD-5 met $+\mathrm{SU}$ ): a randomised controlled trial. Diabetologia. 2009;52(10):2046-55.

51. Diamant M, Van Gaal L, Stranks S, et al. Once weekly exenatide compared with insulin glargine titrated to target in patients with type 2 diabetes (DURATION-3): an open-label randomised trial. Lancet. 2010;375(9733):2234-43.

52. Avogaro A, Delgado E, Lingvay I. When metformin is not enough: pros and cons of SGLT2 and DPP-4 inhibitors as a second line therapy. Diabetes Metab Res Rev. 2018;34(4):e2981.

53. Del Prato S, Nauck M, Duran-Garcia S, et al. Longterm glycaemic response and tolerability of 
dapagliflozin versus a sulphonylurea as add-on therapy to metformin in patients with type 2 diabetes: 4-year data. Diabetes Obes Metab. 2015;17(6): 581-90.

54. Monami M, Liistro F, Scatena A, Nreu B, Mannucci E. Short and medium-term efficacy of sodium glucose co-transporter-2 (SGLT-2) inhibitors: a metaanalysis of randomized clinical trials. Diabetes Obes Metab. 2018;20(5):1213-22.

55. Karagiannis T, Paschos P, Paletas K, Matthews DR, Tsapas A. Dipeptidyl peptidase-4 inhibitors for treatment of type 2 diabetes mellitus in the clinical setting: systematic review and meta-analysis. BMJ. 2012;344:e1369.

56. Investigators OT, Gerstein HC, Bosch J, et al. Basal insulin and cardiovascular and other outcomes in dysglycemia. N Engl J Med. 2012;367(4):319-28.

57. Marso SP, McGuire DK, Zinman B, et al. Efficacy and safety of degludec versus glargine in type 2 diabetes. N Engl J Med. 2017;377(8):723-32.

58. Rosenstock J, Cheng A, Ritzel R, et al. More similarities than differences testing insulin glargine 300 Units/mL versus insulin degludec 100 Units/mL in insulin-naive type 2 diabetes: the randomized Head-to-Head BRIGHT Trial. Diabetes Care. 2018;41(10):2147-54.

59. Philis-Tsimikas A, Klonoff DC, Khunti K, et al. Risk of hypoglycaemia with insulin degludec versus insulin glargine U300 in insulin-treated patients with type 2 diabetes: the randomised, head-to-head CONCLUDE trial. Diabetologia. 2020;63(4): 698-710.

60. Berard L, Antonishyn N, Arcudi K, et al. Insulin matters: a practical approach to basal insulin management in type 2 diabetes. Diabetes Ther. 2018;9(2):501-19.

61. Forst T, Alghdban MK, Fischer A, et al. Sequential treatment escalation with dapagliflozin and saxagliptin improves beta cell function in type 2 diabetic patients on previous metformin treatment: an exploratory mechanistic study. Horm Metab Res. 2018;50(5):403-7.

62. Schreiber SA, Ferlinz K, Haak T. The long-term efficacy of insulin glargine plus oral antidiabetic agents in a 32-month observational study of everyday clinical practice. Diabetes Technol Ther. 2008;10(2): 121-7.

63. Kramer CK, Zinman B, Retnakaran R. Short-term intensive insulin therapy in type 2 diabetes mellitus: a systematic review and meta-analysis. Lancet Diabetes Endocrinol. 2013;1(1):28-34.
64. Lian G, Yue X, Xianxiang Z, Yong L, Weijuan L, Bing C. Insulinization: a promising strategy for the treatment of type 2 diabetes mellitus. Exp Ther Med. 2013;6(5):1300-6.

65. Rorsman P, Eliasson L, Renstrom E, Gromada J, Barg S, Gopel S. The cell physiology of biphasic insulin secretion. News Physiol Sci. 2000;15:72-7.

66. Stumvoll M, Tataranni PA, Stefan N, Vozarova B, Bogardus C. Glucose allostasis. Diabetes. 2003;52(4):903-9.

67. Brown A, Guess N, Dornhorst A, Taheri S, Frost G. Insulin-associated weight gain in obese type 2 diabetes mellitus patients: what can be done? Diabetes Obes Metab. 2017;19(12):1655-68.

68. Hanefeld $M$, Fleischmann $H$, Landgraf $W$, Pistrosch F. EARLY study: early basal insulin therapy under real-life conditions in type 2 diabetics. Diabetes Stoffw Herz. 2012;21:91-7.

69. Hanefeld M, Fleischmann H, Schiffhorst G, Bramlage P. Predictors of response to early basal insulin treatment in patients with type 2 diabetes-the EARLY experience. Diabetes Technol Ther. 2014;16(4):241-6.

70. Genuth S. Exogenous insulin administration and cardiovascular risk in non-insulin-dependent and insulin-dependent diabetes mellitus. Ann Intern Med. 1996;124(1 Pt 2):104-9.

71. Vongries AG. Letter: the UGDP study. JAMA. 1974;230(9):1256-7.

72. UK Prospective Diabetes Study (UKPDS) Group. Intensive blood-glucose control with sulphonylureas or insulin compared with conventional treatment and risk of complications in patients with type 2 diabetes (UKPDS 33). Lancet. 1998;352(9131):837-53.

73. Holman RR, Paul SK, Bethel MA, Matthews DR, Neil HA. 10-year follow-up of intensive glucose control in type 2 diabetes. N Engl J Med. 2008;359(15): 1577-89.

74. Nathan DM, Cleary PA, Backlund JY, et al. Intensive diabetes treatment and cardiovascular disease in patients with type 1 diabetes. $\mathrm{N}$ Engl J Med. 2005;353(25):2643-53.

75. Diabetes Control and Complications Trial (DCCT)/ Epidemiology of Diabetes Interventions and Complications (EDIC) Study Research Group. Intensive diabetes treatment and cardiovascular outcomes in type 1 diabetes: the DCCT/EDIC Study 30-year follow-up. Diabetes Care. 2016;39(5):686-93. 
76. Malmberg K, Ryden L, Efendic S, et al. Randomized trial of insulin-glucose infusion followed by subcutaneous insulin treatment in diabetic patients with acute myocardial infarction (DIGAMI study): effects on mortality at 1 year. J Am Coll Cardiol. 1995;26(1):57-655.

77. Malmberg $\mathrm{K}$, Ryden $\mathrm{L}$, Wedel $\mathrm{H}$, et al. Intense metabolic control by means of insulin in patients with diabetes mellitus and acute myocardial infarction (DIGAMI 2): effects on mortality and morbidity. Eur Heart J. 2005;26(7):650-61.

78. Ritsinger V, Malmberg K, Martensson A, Ryden L, Wedel H, Norhammar A. Intensified insulin-based glycaemic control after myocardial infarction: mortality during 20 year follow-up of the randomised Diabetes Mellitus Insulin Glucose Infusion in Acute Myocardial Infarction (DIGAMI 1) trial. Lancet Diabetes Endocrinol. 2014;2(8):627-33.

79. Origin Trial Investigators. Characteristics associated with maintenance of mean $\mathrm{A} 1 \mathrm{C}<6.5 \%$ in people with dysglycemia in the ORIGIN trial. Diabetes Care. 2013;36(10):2915-22.

80. Origin Trial Investigators, Mellbin LG, Ryden L, et al. Does hypoglycaemia increase the risk of cardiovascular events? A report from the ORIGIN trial. Eur Heart J. 2013;34(40):3137-44.

81. Kosiborod M, Inzucchi SE, Goyal A, et al. Relationship between spontaneous and iatrogenic hypoglycemia and mortality in patients hospitalized with acute myocardial infarction. JAMA. 2009;301(15):1556-644.

82. Bergenstal RM. Glycemic variability and diabetes complications: does it matter? Simply put, there are better glycemic markers! Diabetes Care. 2015;38(8): 1615-21.

83. Lovre D, Fonseca V. Benefits of timely basal insulin control in patients with type 2 diabetes. J Diabetes Complications. 2015;29(2):295-301.

84. Wright A, Burden AC, Paisey RB, Cull CA, Holman RR, Group UKPDS. Sulfonylurea inadequacy: efficacy of addition of insulin over 6 years in patients with type 2 diabetes in the UK. Prospective Diabetes Study (UKPDS 57). Diabetes Care. 2002;25(2):330-6.

85. ORIGIN Trial Investigators, Gilbert RE, Mann JF, et al. Basal insulin glargine and microvascular outcomes in dysglycaemic individuals: results of the Outcome Reduction with an Initial Glargine Intervention (ORIGIN) trial. Diabetologia. 2014;57(7): 1325-31.

86. Lopez-Jaramillo P, Cohen DD, Gomez-Arbelaez D, et al. Association of handgrip strength to cardiovascular mortality in pre-diabetic and diabetic patients: a subanalysis of the ORIGIN trial. Int J Cardiol. 2014;174(2):458-61.

87. Boels AM, Vos RC, Hermans TGT, et al. What determines treatment satisfaction of patients with type 2 diabetes on insulin therapy? An observational study in eight European countries. BMJ Open. 2017;7(7):e016180.

88. Yki-Jarvinen H, Kauppila M, Kujansuu E, et al. Comparison of insulin regimens in patients with non-insulin-dependent diabetes mellitus. N Engl J Med. 1992;327(20):1426-33.

89. Gerstein HC, Yale JF, Harris SB, Issa M, Stewart JA, Dempsey E. A randomized trial of adding insulin glargine vs. avoidance of insulin in people with type 2 diabetes on either no oral glucose-lowering agents or submaximal doses of metformin and/or sulphonylureas. The Canadian INSIGHT (Implementing New Strategies with Insulin Glargine for Hyperglycaemia Treatment) Study. Diabet Med. 2006;23(7):736-42.

90. Yki-Jarvinen H, Kauppinen-Makelin R, Tiikkainen $\mathrm{M}$, et al. Insulin glargine or NPH combined with metformin in type 2 diabetes: the LANMET study. Diabetologia. 2006;49(3):442-51.

91. Kahn SE, Hull RL, Utzschneider KM. Mechanisms linking obesity to insulin resistance and type 2 diabetes. Nature. 2006;444(7121):840-6.

92. Balkau B, Home PD, Vincent M, Marre M, Freemantle N. Factors associated with weight gain in people with type 2 diabetes starting on insulin. Diabetes Care. 2014;37(8):2108-13.

93. Garber AJ. Treat-to-target trials: uses, interpretation and review of concepts. Diabetes Obes Metab. 2014;16(3):193-205.

94. Holman RR, Thorne KI, Farmer AJ, et al. Addition of biphasic, prandial, or basal insulin to oral therapy in type 2 diabetes. N Engl J Med. 2007;357(17): 1716-30.

95. Janka HU, Plewe G, Riddle MC, Kliebe-Frisch C, Schweitzer MA, Yki-Jarvinen H. Comparison of basal insulin added to oral agents versus twice-daily premixed insulin as initial insulin therapy for type 2 diabetes. Diabetes Care. 2005;28(2):254-9.

96. Bretzel RG, Nuber U, Landgraf W, Owens DR, Bradley C, Linn T. Once-daily basal insulin glargine versus thrice-daily prandial insulin lispro in people with type 2 diabetes on oral hypoglycaemic agents (APOLLO): an open randomised controlled trial. Lancet. 2008;371(9618):1073-84.

97. Lingvay I, Legendre JL, Kaloyanova PF, Zhang S, Adams-Huet B, Raskin P. Insulin-based versus triple 
oral therapy for newly diagnosed type 2 diabetes: which is better? Diabetes Care. 2009;32(10): 1789-95.

98. Wright RJ, Frier BM. Vascular disease and diabetes: is hypoglycaemia an aggravating factor? Diabetes Metab Res Rev. 2008;24(5):353-63.

99. International Hypoglycaemia Study Group. Hypoglycaemia, cardiovascular disease, and mortality in diabetes: epidemiology, pathogenesis, and management. Lancet Diabetes Endocrinol. 2019;7(5): 385-96.

100. Standl E, Stevens SR, Armstrong PW, et al. Increased risk of severe hypoglycemic events before and after cardiovascular outcomes in TECOS suggests an atrisk type 2 diabetes frail patient phenotype. Diabetes Care. 2018;41(3):596-603.

101. Holstein A, Plaschke A, Egberts EH. Clinical characterisation of severe hypoglycaemia-a prospective population-based study. Exp Clin Endocrinol Diabetes. 2003;111(6):364-9.

102. Holstein A, Patzer OM, Machalke K, Holstein JD, Stumvoll M, Kovacs P. Substantial increase in incidence of severe hypoglycemia between 1997-2000 and 2007-2010: a German longitudinal populationbased study. Diabetes Care. 2012;35(5):972-5.

103. Bataille V, Ferrieres J, Danchin N, et al. Increased mortality risk in diabetic patients discharged from hospital with insulin therapy after an acute myocardial infarction: data from the FAST-MI 2005 registry. Eur Heart J Acute Cardiovasc Care. 2019;8(3):218-30.

104. Writing Group for the DCCT/EDIC Research Group, Orchard TJ, Nathan DM, et al. Association between 7 years of intensive treatment of type 1 diabetes and long-term mortality. JAMA. 2015;313(1):45-53.

105. Diabetes Control and Complications Trial (DCCT)/ Epidemiology of Diabetes Interventions and Complications (EDIC) Study Research Group. Mortality in type 1 diabetes in the DCCT/EDIC versus the general population. Diabetes Care. 2016;39(8): 1378-83.

106. Nystrom T, Bodegard J, Nathanson D, Thuresson M, Norhammar A, Eriksson JW. Second line initiation of insulin compared with DPP-4 inhibitors after metformin monotherapy is associated with increased risk of all-cause mortality, cardiovascular events, and severe hypoglycemia. Diabetes Res Clin Pract. 2017;123:199-208.

107. Zhuang XD, He X, Yang DY, et al. Comparative cardiovascular outcomes in the era of novel antidiabetic agents: a comprehensive network metaanalysis of 166,371 participants from 170 randomized controlled trials. Cardiovasc Diabetol. 2018;17(1):79.

108. Davies MJ, D’Alessio DA, Fradkin J, et al. Management of hyperglycaemia in type 2 diabetes, 2018. A consensus report by the American Diabetes Association (ADA) and the European Association for the Study of Diabetes (EASD). Diabetologia. 2018;61(12):2461-98.

109. Meneghini LF. Early insulin treatment in type 2 diabetes: what are the pros? Diabetes Care. 2009;32(Suppl 2):S266-S269269.

110. Chiasson JL. Early insulin use in type 2 diabetes: what are the cons? Diabetes Care. 2009;32(Suppl 2): S270-S274274.

111. Raz I, Mosenzon O. Early insulinization to prevent diabetes progression. Diabetes Care. 2013;36(Suppl 2):S190-S197197.

112. Ryan EA, Imes S, Wallace C. Short-term intensive insulin therapy in newly diagnosed type 2 diabetes. Diabetes Care. 2004;27(5):1028-32.

113. Kirkman MS, Briscoe VJ, Clark N, et al. Diabetes in older adults. Diabetes Care. 2012;35(12):2650-64.

114. DDG. S2k-Leitlinie Diagnostik, Therapie und Verlaufskontrolle des Diabetes mellitus im Alter. 2018. https://www.deutsche-diabetes-gesellschaft.de/ fileadmin/Redakteur/Leitlinien/Evidenzbasierte Leitlinien/2018/057_017_LL_Alter_Gesamtdokument_ 20180713.pdf

115. Diabetes Canada Clinical Practice Guidelines Expert Committee. Clinical practice guidelines, Chapter 37: diabetes in older people. 2018. https://www. diabetes.ca/DiabetesCanadaWebsite/media/Healthcare-providers $/ 2018 \% 20$ Clinical $\% 20$ Practice $\% 20$ Guidelines/Ch37-Diabetes-in-Older-People.pdf

116. Neuhauser HK, Adler C, Rosario AS, Diederichs C, Ellert U. Hypertension prevalence, awareness, treatment and control in Germany 1998 and 2008-2011. J Hum Hypertens. 2015;29(4):247-53.

117. Kwon Y, Kim HJ, Park S, Park YG, Cho KH. Body mass index-related mortality in patients with type 2 diabetes and heterogeneity in obesity paradox studies: a dose-response meta-analysis. PLoS One. 2017;12(1):e0168247.

118. Whitmer RA, Karter AJ, Yaffe K, Quesenberry CP Jr, Selby JV. Hypoglycemic episodes and risk of dementia in older patients with type 2 diabetes mellitus. JAMA. 2009;301(15):1565-72.

119. Sarodnik C, Bours SPG, Schaper NC, van den Bergh JP, van Geel T. The risks of sarcopenia, falls and 
fractures in patients with type 2 diabetes mellitus. Maturitas. 2018;109:70-7.

120. Dimitriadis G, Mitrou P, Lambadiari V, Maratou E, Raptis SA. Insulin effects in muscle and adipose tissue. Diabetes Res Clin Pract. 2011;93(Suppl 1): S52-S5959.

121. Pfeiffer AF, Klein HH. The treatment of type 2 diabetes. Dtsch Arztebl Int. 2014;111(5):69-81 (quiz 2).

122. Cimmaruta D, Maiorino MI, Scavone C, et al. Efficacy and safety of insulin-GLP-1 receptor agonists combination in type 2 diabetes mellitus: a systematic review. Expert Opin Drug Saf. 2016;15(sup2): 77-83.

123. Diamant M, Nauck MA, Shaginian R, et al. Glucagon-like peptide 1 receptor agonist or bolus insulin with optimized basal insulin in type 2 diabetes. Diabetes Care. 2014;37(10):2763-73.

124. Rosenstock J, Guerci B, Hanefeld M, et al. Prandial options to advance basal insulin glargine therapy: testing lixisenatide plus basal insulin versus insulin glulisine either as basal-plus or basal-bolus in type 2 diabetes: the GetGoal Duo-2 Trial. Diabetes Care. 2016;39(8):1318-28.

125. Flat-Sugar Trial Investigators. Glucose variability in a 26-week randomized comparison of mealtime treatment with rapid-acting insulin versus GLP-1 agonist in participants with type 2 diabetes at high cardiovascular risk. Diabetes Care. 2016;39(6): 973-81.

126. Cariou B. Pleiotropic effects of insulin and GLP-1 receptor agonists: potential benefits of the association. Diabetes Metab. 2015;41(6 Suppl 1):6S28-S35.

127. Eng C, Kramer CK, Zinman B, Retnakaran R. Glucagon-like peptide-1 receptor agonist and basal insulin combination treatment for the management of type 2 diabetes: a systematic review and metaanalysis. Lancet. 2014;384(9961):2228-34.

128. DeVries JH, Bain SC, Rodbard HW, et al. Sequential intensification of metformin treatment in type 2 diabetes with liraglutide followed by randomized addition of basal insulin prompted by A1C targets. Diabetes Care. 2012;35(7):1446-544.

129. Sikirica MV, Martin AA, Wood R, Leith A, Piercy J, Higgins V. Reasons for discontinuation of GLP1 receptor agonists: data from a real-world cross-sectional survey of physicians and their patients with type 2 diabetes. Diabetes Metab Syndr Obes. 2017;10:403-12.

130. Arakaki RF, Blevins TC, Wise JK, et al. Comparison of insulin lispro protamine suspension versus insulin glargine once daily added to oral antihyperglycaemic medications and exenatide in type 2 diabetes: a prospective randomized open-label trial. Diabetes Obes Metab. 2014;16(6):510-8.

131. Thong KY, Jose B, Sukumar N, et al. Safety, efficacy and tolerability of exenatide in combination with insulin in the Association of British Clinical Diabetologists nationwide exenatide audit. Diabetes Obes Metab. 2011;13(8):703-10.

132. Thong KY, McDonald TJ, Hattersley AT, et al. The association between postprandial urinary C-peptide creatinine ratio and the treatment response to liraglutide: a multi-centre observational study. Diabet Med. 2014;31(4):403-11.

133. Gallwitz B, Guzman J, Dotta F, et al. Exenatide twice daily versus glimepiride for prevention of glycaemic deterioration in patients with type 2 diabetes with metformin failure (EUREXA): an open-label, randomised controlled trial. Lancet. 2012;379(9833): 2270-8.

134. Hinnen D, Strong J. iGlarLixi: a new once-daily fixed-ratio combination of basal insulin glargine and lixisenatide for the management of type 2 diabetes. Diabetes Spectr. 2018;31(2):145-54.

135. Wysham CH, Campos C, Kruger D. Safety and efficacy of insulin degludec/liraglutide (iDegLira) and insulin glargine U100/Lixisenatide (iGlarLixi), two novel co-formulations of a basal insulin and a glucagon-like peptide- 1 receptor agonist, in patients with diabetes not adequately controlled on oral antidiabetic medications. Clin Diabetes. 2018;36(2): 149-59.

136. Sugimoto DH, Dex T, Stager W, Aroda VR. Efficacy of iGlarLixi, a fixed-ratio combination of insulin glargine and lixisenatide, in patients with type 2 diabetes stratified as at high or low risk according to HEDIS measurements. Diabetes Obes Metab. 2018;20(11):2680-4.

137. Buse JB, Vilsboll T, Thurman J, et al. Contribution of liraglutide in the fixed-ratio combination of insulin degludec and liraglutide (IDegLira). Diabetes Care. 2014;37(11):2926-33.

138. Gough SC, Bode B, Woo V, et al. Efficacy and safety of a fixed-ratio combination of insulin degludec and liraglutide (IDegLira) compared with its components given alone: results of a phase 3, open-label, randomised, 26-week, treat-to-target trial in insulinnaive patients with type 2 diabetes. Lancet Diabetes Endocrinol. 2014;2(11):885-93.

139. Scott LJ. Insulin glargine/lixisenatide: a review in type 2 diabetes. Drugs. 2017;77(12):1353-62. 
140. Anderson SL, Trujillo JM. Lixisenatide in type 2 diabetes: latest evidence and clinical usefulness. Ther Adv Chronic Dis. 2016;7(1):4-17.

141. Anderson SL, Trujillo JM. Basal insulin use with GLP-1 receptor agonists. Diabetes Spectr. 2016;29(3):152-60.

142. Wilkinson S, Douglas I, Stirnadel-Farrant H, et al. Changing use of antidiabetic drugs in the UK: trends in prescribing 2000-2017. BMJ Open. 2018;8(7):e022768.

143. Divino V, DeKoven M, Khan FA, Boye KS, Sapin H, Norrbacka K. GLP-1 RA treatment patterns among type 2 diabetes patients in five European countries. Diabetes Ther. 2017;8(1):115-28.

144. Nauck MA. Update on developments with SGLT2 inhibitors in the management of type 2 diabetes. Drug Des Devel Ther. 2014;8:1335-800.

145. van Baar MJB, van Ruiten CC, Muskiet MHA, van Bloemendaal L, van Raalte DH. SGLT2 inhibitors in combination therapy: from mechanisms to clinical considerations in type 2 diabetes management. Diabetes Care. 2018;41(8):1543-56.

146. John M, Gopinath D, Jagesh R. Sodium-glucose cotransporter 2 inhibitors with insulin in type 2 diabetes: clinical perspectives. Indian J Endocrinol Metab. 2016;20(1):22-31.

147. Merovci A, Mari A, Solis-Herrera C, et al. Dapagliflozin lowers plasma glucose concentration and improves beta-cell function. J Clin Endocrinol Metab. 2015;100(5):1927-32.
148. Abdul-Ghani M, Al Jobori H, Daniele G, et al. Inhibition of renal sodium-glucose cotransport with empagliflozin lowers fasting plasma glucose and improves beta-cell function in subjects with impaired fasting glucose. Diabetes. 2017;66(9): 2495-502.

149. Al Jobori H, Daniele G, Adams J, et al. Empagliflozin treatment is associated with improved beta-cell function in type 2 diabetes mellitus. J Clin Endocrinol Metab. 2018;103(4):1402-7.

150. Kaneto H, Obata A, Kimura T, et al. Beneficial effects of sodium-glucose cotransporter 2 inhibitors for preservation of pancreatic beta-cell function and reduction of insulin resistance. $\mathrm{J}$ Diabetes. 2017;9(3):219-25.

151. Tang H, Cui W, Li D, et al. Sodium-glucose cotransporter 2 inhibitors in addition to insulin therapy for management of type 2 diabetes mellitus: a meta-analysis of randomized controlled trials. Diabetes Obes Metab. 2017;19(1):142-7.

152. Liu J, Li L, Li S, et al. Effects of SGLT2 inhibitors on UTIs and genital infections in type 2 diabetes mellitus: a systematic review and meta-analysis. Sci Rep. 2017;7(1):2824.

153. Lega IC, Bronskill SE, Campitelli MA, et al. Sodium glucose cotransporter 2 inhibitors and risk of genital mycotic and urinary tract infection: a populationbased study of older women and men with diabetes. Diabetes Obes Metab. 2019;21(11):2394-404. 